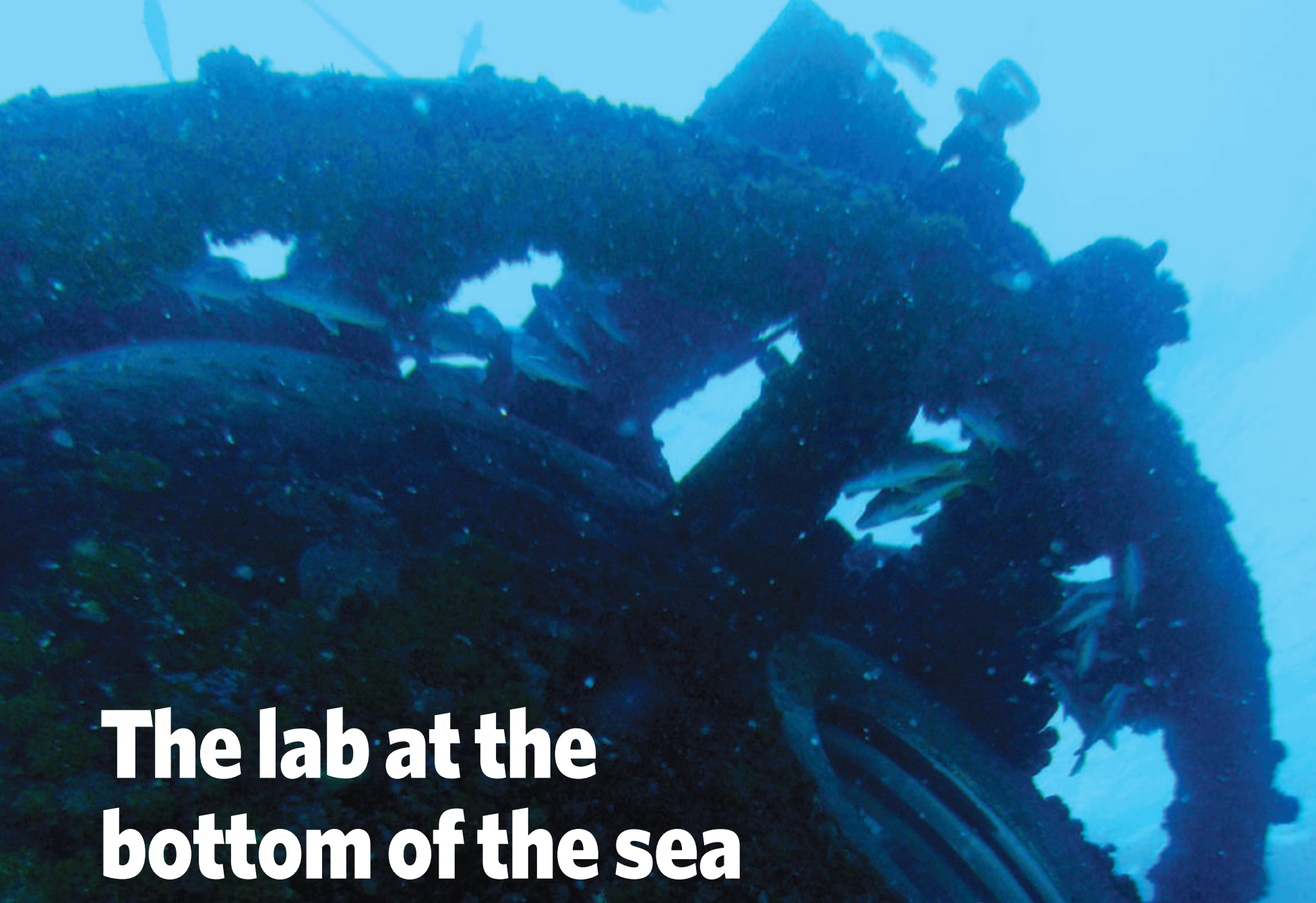

\author{
The best way to study life beneath the waves is to live \\ there. Mark Schrope describes his experiences in the \\ world's longest-running undersea laboratory.
}

$$
\begin{aligned}
& \mathrm{t} \\
& \mathrm{K} \\
& \mathrm{g}
\end{aligned}
$$

$t$ is night on Conch Reef in the Florida Keys, and Niels Lindquist is running a thin green plane of laser light through a lone sponge. The psychedelic display captures the attention of a rather large, green moray eel. As Lindquist watches, the eel inspects the laser light, decides it doesn't approve and finds another way around, swimming right down the side of Lindquist's leg. It is only when the eel has vanished into the night that Lindquist notices that his dive buddy has risen to a safe distance with the wariness most divers accord such beasts. Lindquist, though, had been completely at ease.

Lindquist's sangfroid comes from the sort of experience and familiarity most divers can't even dream of. A chemical ecologist from the University of North Carolina in Chapel Hill, he has spent the past ten days underwater, living and working at the world's only underwater long-term research station - the Aquarius Undersea Laboratory, which sits next to Conch Reef. Aquarius is roughly the size of a school bus, 15 metres under the waves and 6.5 kilometres off the Florida coast. Managed by the University of North Carolina in Wilmington for the US National Oceanic and Atmospheric Administration (NOAA), the laboratory began operating in 1993. Over the years, according to its director, Andrew Shepard, it has sometimes been hard to convince people that the facility is worth its annual operating budget, currently about US\$2 million. Since 2007 , in part to provide clearer justification, Aquarius's chief scientist, Ellen Prager, and her colleagues have been working to better define the facility's mission. One research focus she and her colleagues are highlighting is technology development for long-term ocean observing - an established priority for NOAA. The laser that was illuminating that sponge is one such technology.

But there is more to the sponge work than a technological shakedown cruise. It is the latest part of a set of Aquarius-based studies of the roles that sponges play in reef ecology. Sponges have long been known to be prodi- gious pumpers of water ${ }^{1}$, but these expeditions have provided the first precise figures on quite how prodigious the pumping powers are - findings that could have implications for reef research worldwide. Such work can be done without a home under the waves, but it takes a lot longer, and it might not lead to the same insights and achievements. An 'aquanaut' in Aquarius can spend 12 hours a day diving, a tally that could take weeks to accomplish with regular scuba dives from the surface. The sustained access that Aquarius offers also makes researchers much more responsive to anything untoward.

Aquarius is not just about convenience, though. Most scuba divers will tell you that when you pause to really watch a section of a coral reef you are sure to spot subtle details you would have missed if you had kept swimming. Researchers who have lived in Aquarius say that experience is magnified many times over. "You're looking at the complete ecosystem if you're working from Aquarius," says 
Chris Martens of the University of North Carolina in Wilmington. "You gain so much, so fast."

Aquarius is not just a home for aquanauts - and the occasional astronaut who comes for some zero- $g$ simulation time and experience of cramped conditions. There are plenty of snapper and other fish living in the waters below the coral and algae-bedecked lab, utterly at ease with the human residents. Divers making their way into the hole at the end of the lab that leads into the 'wet porch' entryway are often greeted by chub fish swimming between their legs. The lab is filled with normal air under enough pressure to keep water from entering. Burps of air periodically escape the entrance hole, resonating inside the wet porch like the sound of a draining tub.

From the wet porch, visitors enter a small workroom that houses research equipment and a curtained toilet. Every other room is visible to the world via webcams, creating a sort of human fishbowl effect. "You get used to it," says Lindquist, with a laugh and in a voice of slightly higher pitch than normal, due to the extra atmosphere-and-a-bit of pressure.

The next chamber is known as the main lock. On one side is a bank of monitors and controls for the lab's life-support system, and a computer. On the other is a simple kitchen where aquanauts prepare mainly freeze-dried meals, and a table that sits next to one of the portholes. "We get friends coming to the view ports all the time, especially at night," says Lindquist. Soon after, a large barracuda swims by. The final space is the kind that someone seeking to make a sale might describe as cosy: tripledecker bunks on either side of the structure for four researchers and two technicians. "There's

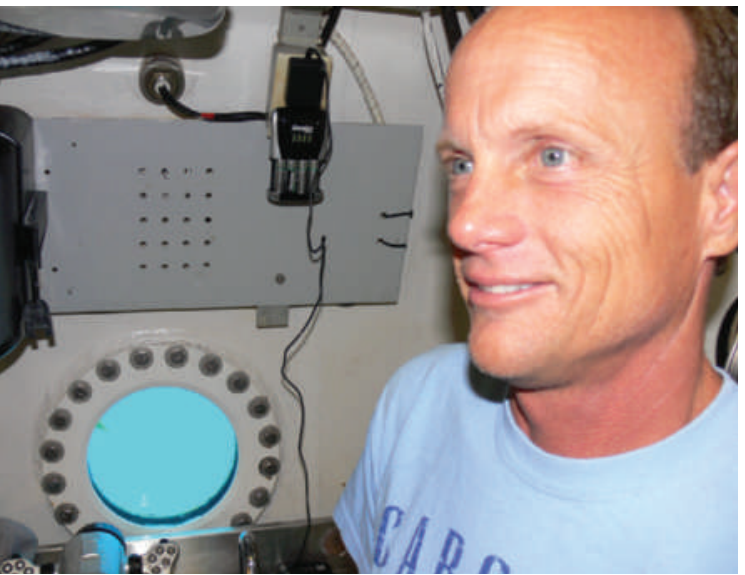

Niels Lindquist, safe from eels inside Aquarius.

well understood upwellings, ocean water tends to move only horizontally. "A few millimetres of vertical velocity gets people's attention," says Hench. That's why, on a previous mission, the team had been astonished to measure a vertical-flow rate of 25 centimetres per second from a single giant barrel sponge "When I first saw that I couldn't believe it," says Hench, "because you just don't see that in nature."

More measurements, though, proved that the rates were real. In fact, some vase sponges can pump more than 100,000 times their own volume in a single day. A modest-sized giant barrel sponge can pump 15,000 litres per hour, giving a weekly volume roughly not a lot of personal space," says Jim Hench, a veteran aquanaut from Stanford University in California. "Unless you're outside - then it's great."

The North Carolina team's sponge-studying mission last September lasted eight working days - a typical length for the facility's eight or so missions a year - largely devoted to just four individual star sponges on Conch Reef. Like patients in an emergency department, each sponge was wired up at one time or another with a full complement of monitors and sampling devices that linked back to Aquarius: a device for measuring water flow, a mass spectrometer to calculate the isotopic signatures of nitrogen and other compounds going into and coming out of the sponge, and an autoanalyser to record nutrient concentrations.

\section{Pump it up}

The team's most startling results have been on the sheer amount of water that the sponges pump. Below the waves and away from fairly

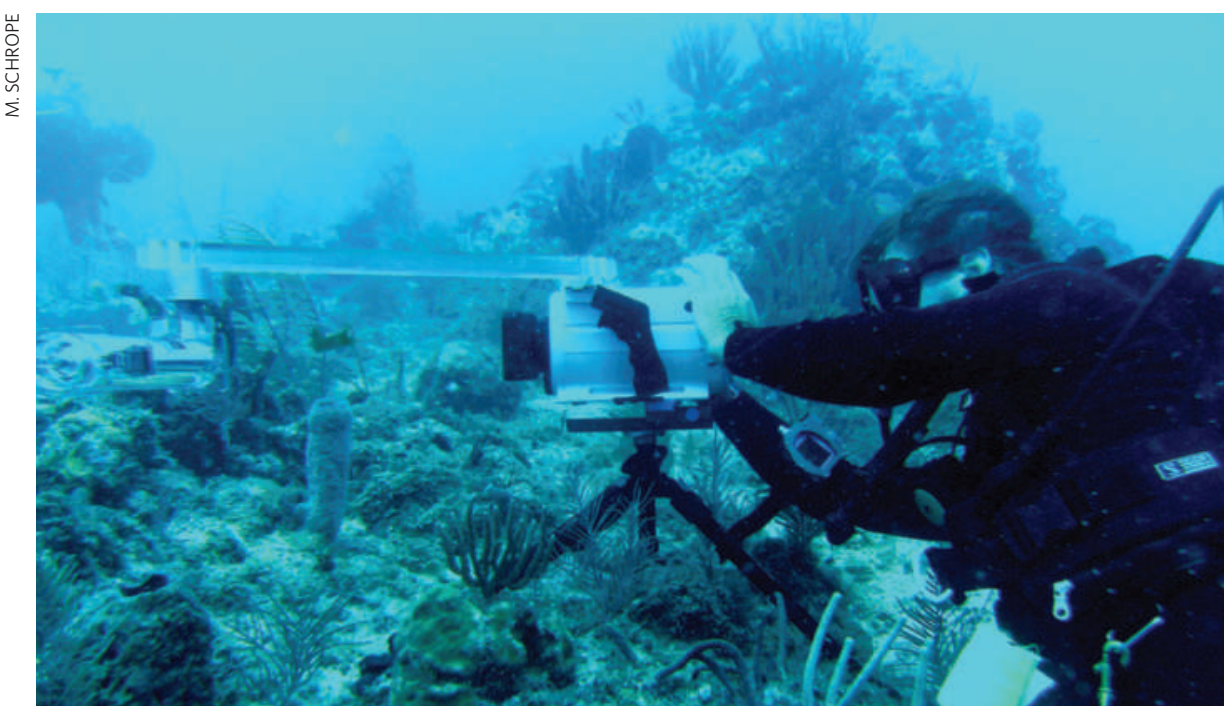

Measuring how fast water is pumped out by sponges provides clues about the health of a reef.

equal to that of an Olympic-sized swimming pool. Some sponges have since proved less siphontastic; but in terms of flow for a given body size, some were even more vigorous in their pumping than the giant barrel sponges.

The plumbing that enables the sponges to work at these impressive rates consists of a system of channels and chambers spread throughout the sponges' bodies. Cells known as choanocytes, which line the pumping chambers, are equipped with waving flagella that move water past filter-feeding components and out of the sponge. For decades, researchers thought that water currents assisted the sponge's pumping action. But work on Conch Reef suggests that the choanocytes work alone to establish those impressive rates.

More surprising still is that barrel sponges in various parts of the reef will occasionally stop pumping in unison for periods of up to several hours for no apparent reason. "There's a rhythm out there nobody has ever seen before," says Lindquist. What triggers this synchronized action is not clear. In the September mission, the team recorded that synchronized slowdowns, but not complete stoppages, seemed to be happening in the reef's stinker sponges - so called because of the sulphurous smell they exude when brought to the surface

The ways of the sponge are important because what comes out is not what goes in. Sponges are remarkably efficient at pulling particles and plankton out of the water during the few seconds that the water remains in their bodies ${ }^{2}$. This means that they are crucial for cleaning the water and helping to create the clear conditions that many reefs require to thrive. But they don't just change the particulate content of the water - they also change its chemical content. Much of the responsibility for these changes can be laid at the door not of the sponges but of the microbes that live within them - high-microbial-abundance (HMA) sponges can be $50 \%$ bacterial by mass. 
